\title{
ABANDONED LAND CLASSIFICATION USING CLASSICAL THEORY METHOD
}

\author{
Sužiedelyte Visockiene Jūrate ${ }^{1}$, Tumeliene Egle ${ }^{1,2}$ \\ ${ }^{1}$ Vilnius Gediminas Technical University, Lithuania \\ ${ }^{2}$ Vytautas Magnus University, Agriculture Academy, Lithuania
}

\begin{abstract}
According to the official statistics the areas of abandoned agricultural land in Lithuania are gradually decreasing, but very slightly. The aim of this study is to research spatial determination and abandoned land classification in the territory of Vilnius District Municipality. Vilnius District Municipality was chosen for the research because it, although located near the capital of the country and has a high population density, it is still the district having the largest percent of abandoned land plots. A fast, cost-effective and sufficiently accurate method for determination of abandoned land plots would allow to constantly monitor, to fix changes and foresee the abandoned land plots reduction possibilities. In the study there was used the multispectral RGB and NIR colour Sentinel-2 satellite images, the layer of the administrative boundary of Vilnius County and layer of abandoned agriculture land, which is available in Lithuanian Spatial Information Portal (www.geoportal.lt). The data was processed by Geographic Information System (GIS) techniques using classical classification Region Growing Algorithm. The research shows that NIR image classification result is more reliable than the result from RGB images.

Key words: abandoned land, RGB, NIR, spatial resolution, Remote Sensing.
\end{abstract}

\section{Introduction}

Many countries, including Lithuania, analyze the problems of abandoned agricultural lands that are no longer used for their intended purpose. Robust data on agricultural abandonment is important to obtain though, because abandonment has strong environmental implications, affecting, for example, soil stability, carbon sequestration, water quality and nutrient cycling (MacDonald et. al., 2000; Moreira, Russo, 2007; Ramankutty et. al., 2007; Stoate et. al., 2001; Alcantara et. al., 2012). Therefore, better monitoring of agricultural land abandonment is essential to understanding the trajectories and determinants of agricultural land-use change and guiding land-use policies (Prishchepov et. al., 2012). Properly defining abandoned agriculture is not easy. Because abandoned agricultural areas are in transition, the land-use change is without fixed patterns, and often non-linear (Lambin, Meyfroidt, 2011; Alcantara et. al., 2012). Abandoned agriculture is the result of a land owner's decision to reduce the intensity of use of land for agriculture (including grazing) for an undetermined period of time; based on either natural, socioeconomic, or personal constrains. The decision to abandon an agricultural area can precede the actual abandonment by months or even years, depending on the type of agricultural use, and even more time can expire before abandoned agriculture can be detected via remote sensing (Alcantara et. al., 2012). Vice versa, fallow periods are part of the typical crop rotation cycle, making it difficult to ascertain if a field has been truly abandoned or is just awaiting future use. However, as more time expires, it becomes more obvious that a field is abandoned, especially if shrubs and trees start to grow on former fields, since woody plants make it increasingly costly to start agricultural use again, and farmers will typically avoid woody growth on their fields (Alcantara et. al., 2012).

Due to high emigration of working age people Lithuania can be attributed to the regions with higher risk of farmland abandonment, therefore, it can be predicted that areas of abandoned land, especially in sparsely populated areas in Lithuania, may grow in the future.

In Lithuania abandoned land is identified using remote sensing methods, but only in the stage, when they are overgrown with woody plants. For and effective way to solve the problems of abandoned lands and to update the data it is important to choose modern, inexpensive but relatively accurate ways to determine abandoned lands and their size.

Information about land-cover could be derived from Remote Sensed data at various spectral bands images. The principle from of deriving land-cover information from remotely sensed images is classification (Prasad, Thenkabail, 2016). Color has been a great help in identifying objects for many 
years. It is the by-product of the spectrum of light, as it is reflected or absorbed, as received by the human eye and processed by the human brain (Azmi et. al., 2010).

Authors using classical object classification method did research tests with RGB and NIR colour images.

\section{Study area}

The territory of Lithuania is divided into 10 counties. Vilnius District Municipality (Fig. 1), which is the part of Vilnius County, is selected for this research, because the majority of abandoned agricultural land evaluating the total area of each Municipality are situated in Vilnius District Municipality (Suziedelyte et. al., 2019). Abandoned agricultural areas are being identified by the state owned enterprise The National Land Fund (Order of the Minister, 2002).

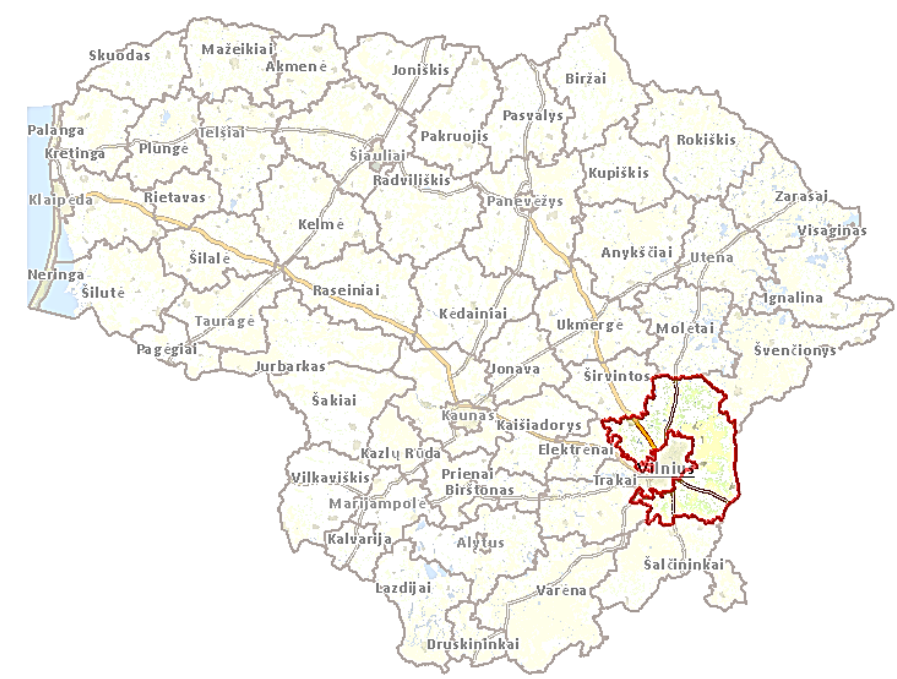

Fig. 1. Study region - Vilnius district municipality (source: $\underline{w w w . r e g i a . l t)}$

\section{Method of research and materials}

The research data were collected from Lithuanian Spatial Information Portal (LSIP) www.geoportal.lt Data time: autumn 2018. Data sources (Fig. 2):

1. Sentenel-2 Red Green Blue (RGB) and Near-infrared (NIR) colour images in Lithuanian coordinate system (LKS94) (2018-09-07);

2. The layer of administrative boundary of Vilnius County in LKS94;

3. The layer of abandoned land in LKS94.

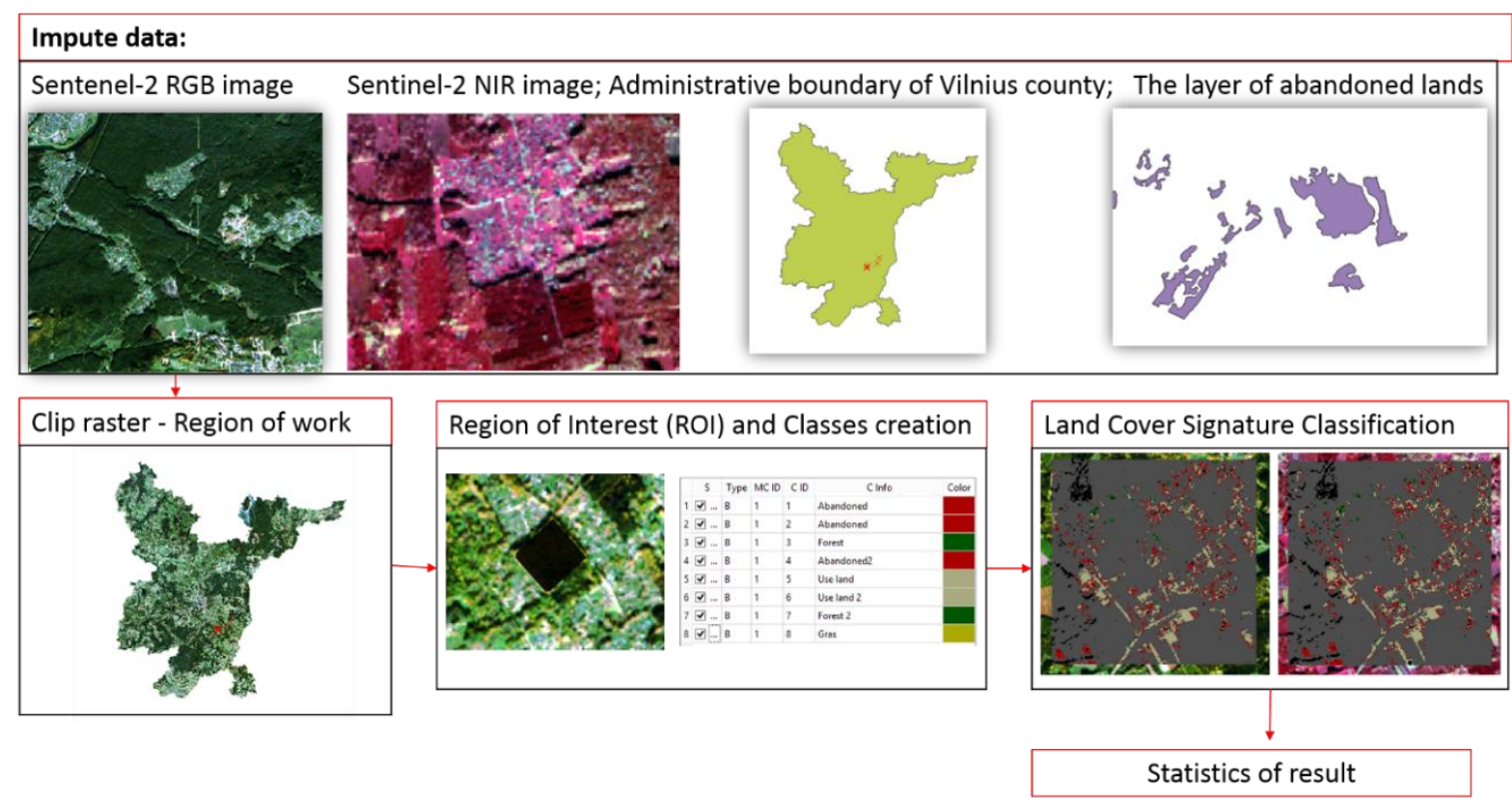

Fig. 2. Data and technological process of land classification 
The principle and categories of deriving land-cover (vegetation species map) result from remotely sensed images is supervised (human-guided) or unsupervised (calculated by software) classification (or segmentation). The supervised classification could be performed by manual interpretation or automated. In the manual method operator digitalizing of the land-cover boundaries using GIS system, but this data is expensive and involving many work hours. The traditionally in classification used the clustering classification algorithms K-mean and ISODATA (Iterative Self-Organizing Data Analysis Technique A) involved iterative procedures by Distance Functions $D i(x)$. The Distance between pixels in feature space is the measure of similarity and scaled in pixels, radiance or reflectance. The relative distances may change when data are calibrated (digital counts $=\Rightarrow$ radiance) or atmospherically corrected or rescaled in ways that treat different spectral bands differently (CEE, 2018). Therefore, it is important to use for classification calibrated image. The K-mean is to reduce the variability within the cluster. Many variations of the K-means algorithm have been developed (CEE, 2018; Abbas et. al., 2016).

The ISODATA algorithm is essentially a refinement of the K-Means algorithm. The specific refinements are (CEE, 2018): clusters that have too few members are discarded; clusters that have too many members are split into two new cluster groups; Clusters that are too large (too disperse) are split into two new cluster groups; If two cluster centres are too close together they are merged. In the study authors are used the Region Growing Algorithm allows to select pixels similar to a seed (image) one, considering the spectral similarity (spectral distance) of adjacent pixels (Region Growing Algorithm, 2018). Land cover are identified to the classes and macro classes with an arbitrary ID codes. In this study we distinguished the vegetation Macro class (ID 1) and class names - abandoned land (ID1), forest land (ID2), land-user (ID3) and unclassified land. The spectral characteristics of reference land cover classes are calculated considering the values of pixels under each Regions of Interest (ROI) having the same Class ID (or Macro class ID). Therefore, the classification algorithm classifies the whole image by comparing the spectral characteristics of each pixel to the spectral characteristics of reference land cover classes. In case of pixels falling inside overlapping regions or outside any spectral region, it is possible to use additional classification algorithms (Minimum Distance, Maximum Likelihood, Spectral Angle Mapping) considering the spectral characteristics of the original input signature. All algorithms could be find in the references (Region Growing Algorithm, 2018; Richards \& Jia, 2006). Minimum Distance algorithm calculates the Euclidean distance $d(x, y)$ between spectral signatures of image pixels and training spectral signatures, according to the following equation (Region Growing Algorithm, 2018):

$d(x, y)=\sqrt{\sum_{i=1}^{n}\left(x_{-} i-y_{-} i\right)^{2}}$

where: $x$ - spectral signature vector of an image pixel; $y$ - spectral signature vector of a training area; $n$ - number of image bands.

The Euclidean Distance is 0 when signatures are identical and tends to increase according to the spectral distance of signatures. Therefore, the distance is calculated for every pixel in the image, assigning the class of the spectral signature that is closer, according to the following discriminant function (Richards and Jia, 2006). Maximum Likelihood algorithm calculates the probability distributions for the classes, related to Bayes' theorem, estimating if a pixel belongs to a land cover class. In particular, the probability distributions for the classes are assumed the form of multivariate normal models (Richards and Jia, 2006). In order to use this algorithm, a sufficient number of pixels is required for each training area allowing for the calculation of the covariance matrix. The discriminant function, described by Richards and Jia (2006), is calculated for every pixel as:

$g_{k(x)}=\ln p\left(C_{k}\right)-\frac{1}{2} \ln \left|\sum k\right|-\frac{1}{2}\left(x-y_{k}\right)^{t} \sum_{k}^{-1}\left(x-y_{k}\right)$

where: $C_{k}$ - land cover class $\mathrm{k}$; $\mathrm{x}$ - spectral signature vector of a image pixel; $p\left(C_{k}\right)$ - probability that the correct class is $C_{k} ; \| \sum k \mid$ - determinant of the covariance matrix of the data in class $C_{k} ; \Sigma \mathrm{k}-1-$ inverse of the covariance matrix; $y_{k}-$ spectral signature vector of class $\mathrm{k}$.

The Spectral Angle Mapping calculates the spectral angle between spectral signatures of image pixels and training spectral signatures. The spectral angle $\theta$ is defined as (Kruse et. al., 1993): 
$\theta(x, y)=\cos ^{-1}\left(\frac{\sum_{i=1}^{n} x_{i} y_{i}}{\left(\sum_{i=1}^{n} x_{i}^{2}\right)^{1 / 2} *\left(\sum_{i=1}^{n} y_{i}^{2}\right)^{1 / 2}}\right)$

The spectral angle goes from 0 , when signatures are identical, to 90 when signatures are completely different.

\section{Discussions and Results}

1.Results from RGB colour images.

RGB color images $10 \times 10 \mathrm{~m}$ spatial resolution was obtained from LSIP. Land classification mode (abandoned, forest and land-user) in ROI 200×200-pixel square area and layer of abandoned agriculture land from LSIP was used for analysis. Digitalizing segment matching the abandoned land area in RGB colour images were separated. Forest and land-used area segments were also introduced. These objects are easily identifiable in the images. Classification according to the colour spectrum of entered objects was performed to use GIS technology. General result of created classes Fig. 3.

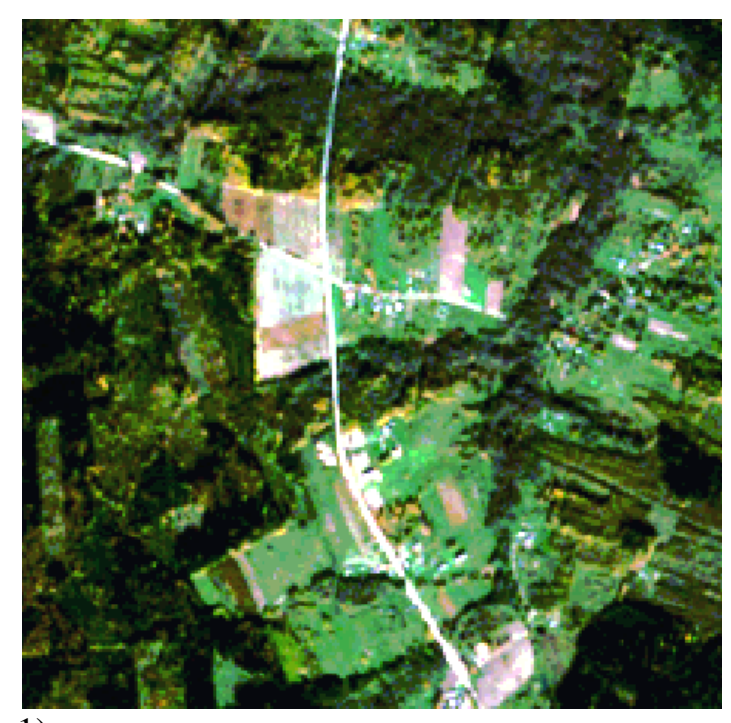

1)

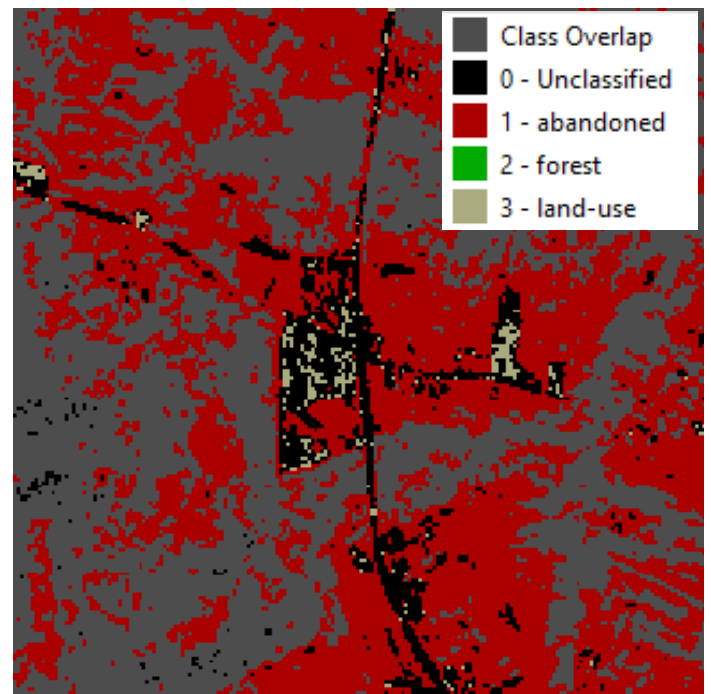

2)

Fig. 3. RGB image classification result: 1) RGB image; 2) classification result

Besides the selected objects classes there is also unclassified objects (black colour) and class overlap objects (grey colour) visible in Fig. 3, part 2). The color spectrum of forest objects is identical to the color spectrum of abandoned land, so in the results the forest is an overlapping class. For more accurate assessment of classification characteristics between classes are presented (Table 1), they describe the compatibility of colour spectrum between classes.

Table 1

Characteristics between classes

\begin{tabular}{|l|c|c|c|}
\hline $\begin{array}{c}\text { Between } \\
\text { Classes name-Class name }\end{array}$ & $\begin{array}{c}\text { Spectral } \\
\text { angle, } \boldsymbol{\theta}^{\mathbf{0}}\end{array}$ & $\begin{array}{c}\text { Euclidean distance } \\
\boldsymbol{d}(\boldsymbol{x}, \boldsymbol{y})\end{array}$ & $\begin{array}{c}\text { Bray-Curtis } \\
\text { similarity*, \% }\end{array}$ \\
\hline Abandoned - Forest & 0,27 & 311,99 & 99,65 \\
\hline Abandoned - Land-use & 1,02 & 1175,69 & 98,53 \\
\hline Forest - Land-use & 1,28 & 1466,27 & 98,19 \\
\hline
\end{tabular}

*The Bray-Curtis similarity is calculated as percentage and ranges from 0 when signatures are completely different to 100 when spectral signatures are identical.

Spectral angle $\theta$ close to zero between Abandoned and Forest classes shows that the classification between these classes overlaps. This is also evidenced by the high degree of similarity of color spectrum $99,65 \%$. Better situation is when you compare Abandoned - Land-user and Forest - Landuser classes. Similarity of color spectrum is $98,53 \%$ and $98,19 \%$. Results of classification of separate classes is showed in Fig. 4. 

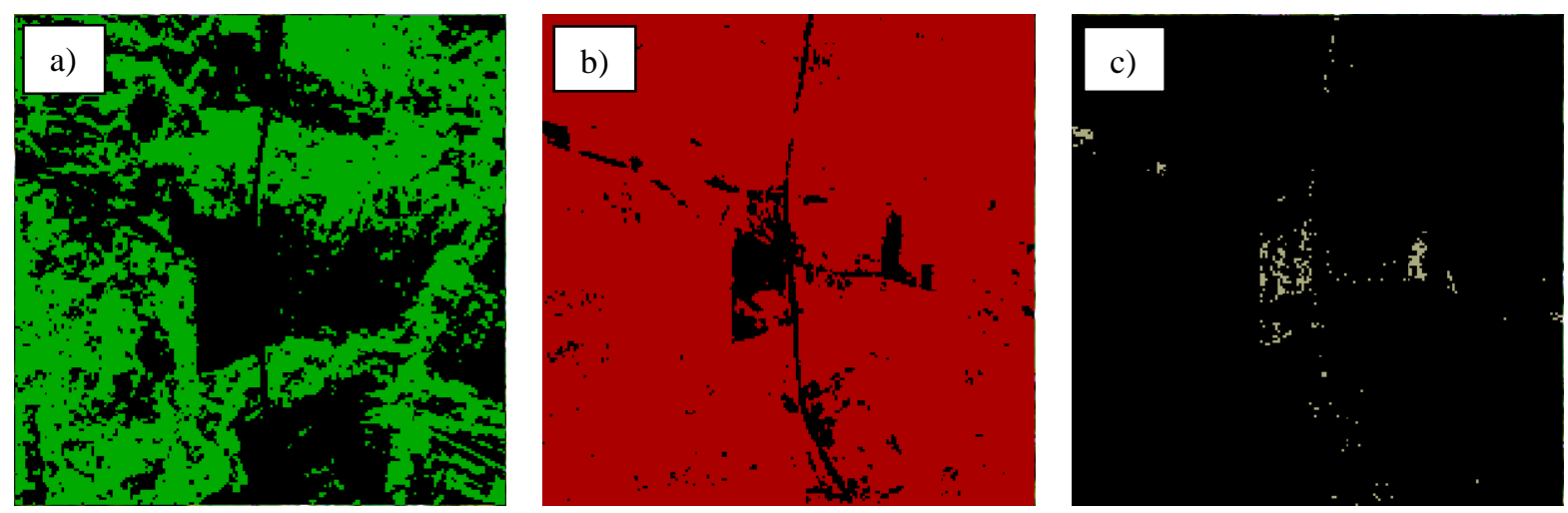

Fig. 4. Results of classification: a) forest land; b) abandoned land; c) land-use

From Fig. 4 it is clear that the biggest part of abandoned land consists from forest areas, small part from land-user class objects. In Fig. 5 presented a general view of forests and abandoned land classification images.

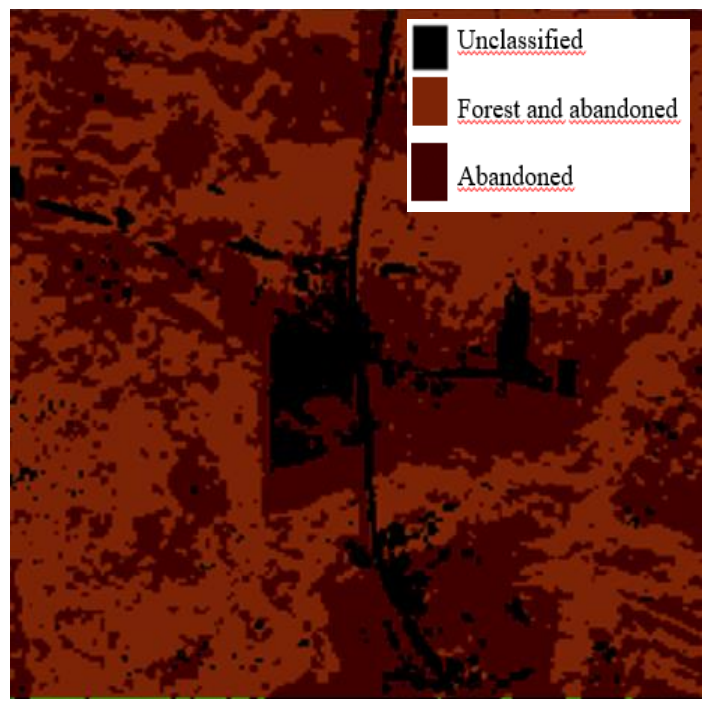

Fig. 5. A general view of forest and abandoned land classification

The dark brown colour in the Fig. 5 is an unclassified object in the forest classification result and abandoned land class object. Light brown colour - forest and an abandoned class together. Black colour - an unclassified land in the forest and an abandoned class. The dark brown layer has abandoned land segments, but the result must be checked and field measurements need to be performed.

2. Results from NIR colour images.

Land-cover classification result used Sentinel-2 NIR colour image data presented in Fig. 6.

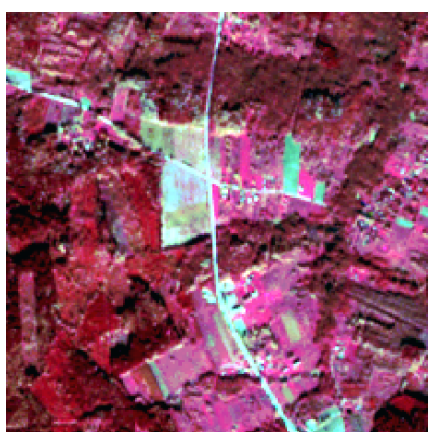

1)

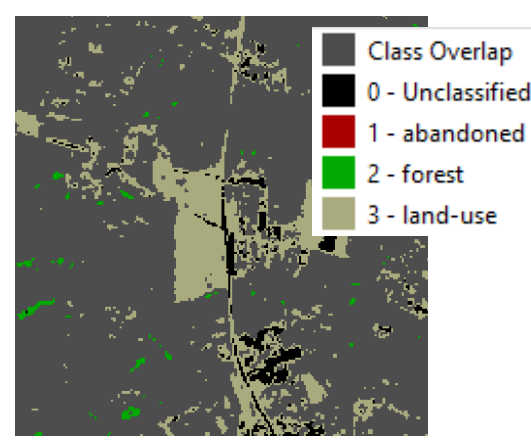

2)

Fig. 6. NIR image classification result: 1) NIR image; 2) classification results 
To evaluate classification accuracy of NIR colour images characteristics between classes are presented in Table 2.

Table 2

Characteristics between classes

\begin{tabular}{|c|c|c|c|}
\hline $\begin{array}{c}\text { Between } \\
\text { Classes name-Class name } \\
\end{array}$ & Spectral angle, $\theta^{0}$ & $\begin{array}{c}\text { Euclidean distance } \\
d(x, y)\end{array}$ & $\begin{array}{c}\text { Bray-Curtis } \\
\text { similarity*, \% }\end{array}$ \\
\hline Abandoned - Forest & 4,63 & 335,29 & 89,82 \\
\hline Abandoned - Land-use & 26,98 & 1311,14 & 76,24 \\
\hline Forest - Land-use & 31,06 & 1522,89 & 68,73 \\
\hline
\end{tabular}

Obtained classification results in this method are much better. Spectral angle between abandoned and forest classes is $4,63^{\circ}$. Which means that colour spectrum results overlap between these classes but less than when the Sentinel-2 RGB colour data was used. Similarity of colour spectrum is $89,82 \%$. This result is also better than RGB. Compared results from other layers are also significantly better when Sentinel-2 NIR data used. The results from separate classes and merged layers of forest and abandoned lands are shown in Fig.7 and Fig. 8.
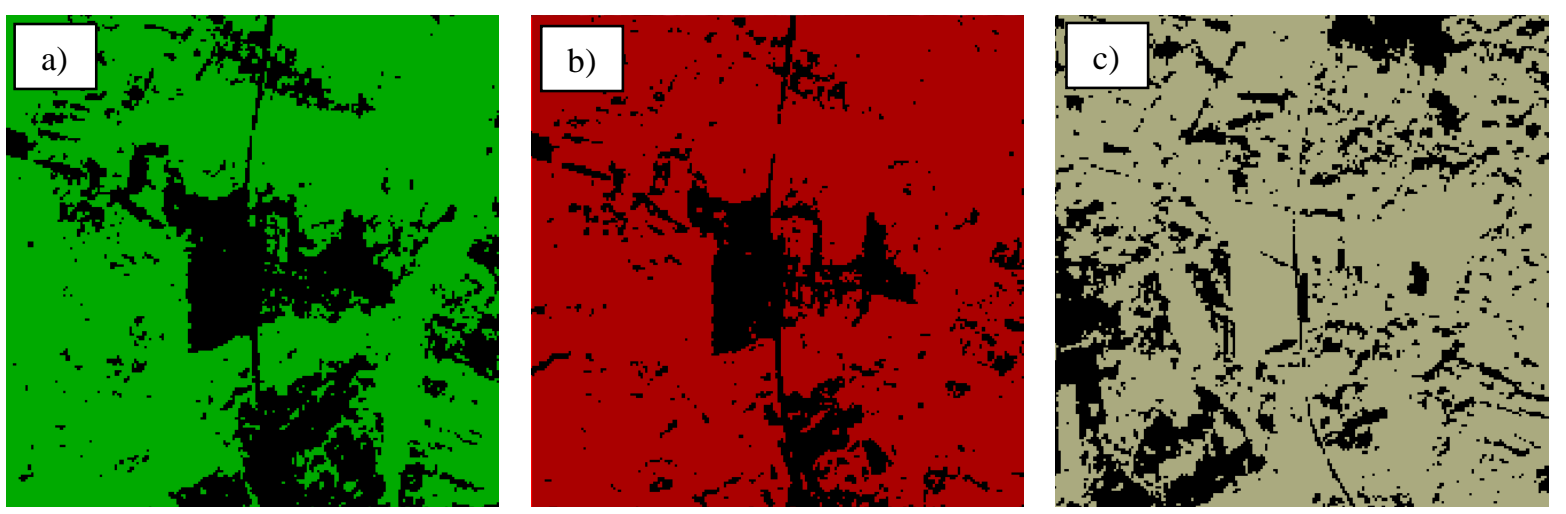

Fig. 7. Results of separate classes: a) forest; b) abandoned land; c) land-user

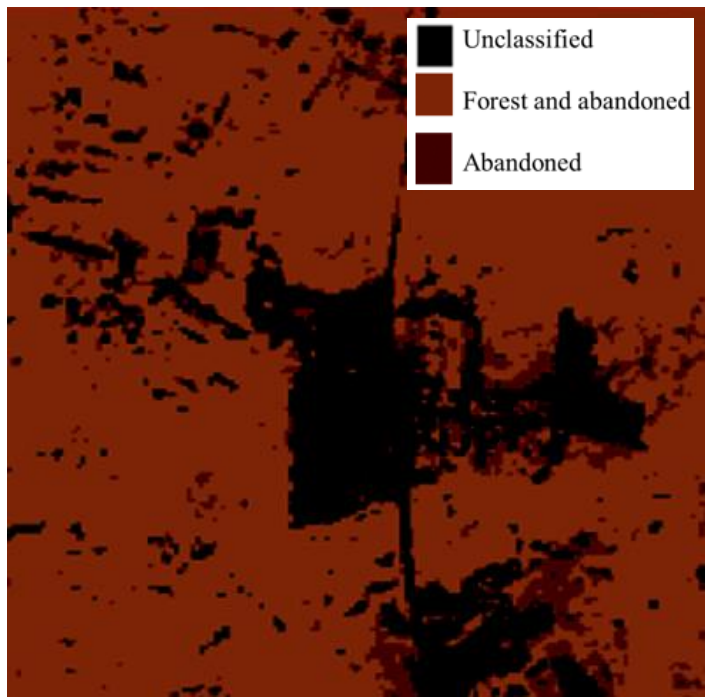

Fig. 8. Merged layers of forest and abandoned land

In the general drawing of forests and abandoned land the data of the dark brown layer is significantly less than what it was in Fig. 5. The inspected areas decreased, because the number of abandoned lands was reduced (Fig.8). A general drawing of classification results and abandoned land from LSIP is presented in figure 9 . 


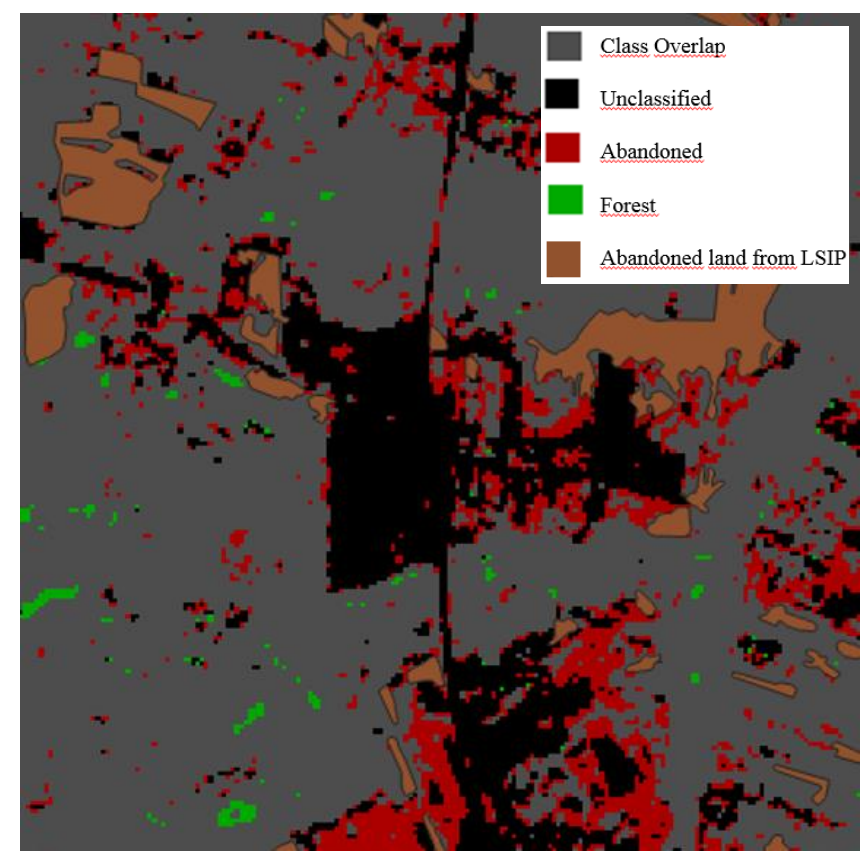

Fig. 9. A general view of the classification and the layer of abandoned land

Figure 9 shows that the abandoned land layer (from LSIP) not cover the abandoned land layer, identified by the classification method, everywhere. The classification results need to be checked locally. The discrepancy may also be due to the fact that the abandoned land from the LSIP layer has a fixed area of a smallest spatial object $-0,10$ ha (Order of the Minister, 2013). When classification method was used the abandoned land of all sizes was identified. For more accurate result the higher image resolution should be used.

\section{Conclusions and proposals}

Region Growing Algorithm can be used to classify Sentinel-2 RGB and NIR data and be used to deduct the similarity of view pixels' colour spectrum of excluded classes. Research with $10 \times 10 \mathrm{~m}$ spatial resolution RGB colour images shows that after the classification of forests, abandoned and used land, the colour spectrum similarity between the forest and abandoned land is $99 \%$. The number of abandoned areas after the classification is high. To check the result field measurements, which are costly and require considerable time, should be carried out. The results from the NIR classification photos are about $10 \%$ better than the results of the RGB classification. The similarity of the colour spectrum of this data between forest and abandoned land classes is $89 \%$. In a general view of forests and abandoned lands, areas of abandoned land are distinguished. Abandoned land areas in NIR photos are far smaller than in the RGB. Part of the abandoned land identified in the RGB image merges into the forest areas in NIR data.

The study shows that it is difficult to precisely distinguish abandoned lands because of the overlapping spectrum of abandoned land and forest classes. To solve this problem it would be appropriate to distinguish the classes of other lands: roads, waters, built-up areas, etc.

Image resolution also influences the result. The higher image resolution $(0.25-1.0 \mathrm{~m})-$ the more reliable classification result. However, this should be based on research. It would also be useful to perform the research with data from different seasons when the pixels colour spectrum of objects is different.

Clearly, the classification results need to be checked locally.

\section{References}

1. Abbas A. W.; Abid S. A. R.; Ahmad N.; Ali Khan M. A. (2016) K-Means and ISODATA Clustering Algorithms for Landcover Classification Using Remote Sensing. Sindh Univ., Res. Journal, 48(2):315-318.

2. Alcantara C., Kuemmerle T., Prishchepov A.V., Radeloff V.C. (2012) Mapping abandoned agriculture with multi-temporal MODIS satellite data. Remote Sensing of Environment, 124 (2012) 334-347. 
3. Azmi M. A. S. B., Mazli N. B., Yusof Y., Hassan M. F. H. A. (2010) Study of RGB Color Classification Using Fuzzy Logic. ETERD'10 Proceeding 2010.

4. CEE 6150 (2018) Digital Image Processing. Unsupervised Classification. In the internet site: http://ceeserver.cee.cornell.edu/wdp2/cee6150/lectures/dip11_clustering_sp11.pdf

5. Kruse F. A., Lefkoff A. B., Boardman J. W., Heidebrecht K. B., Shapiro A. T., Barloon P. J., Goetz A. F. H. (1993) The spectral image processing system (SIPS) - interactive visualization and analysis of imaging spectrometer data. Remote Sensing of Environment, 44, 2-3: 145-163.

6. Lambin E. F., Meyfroidt P. (2011) Global land use change, economic globalization, and the looming land scarcity. Proceedings of the National Academy of Sciences of the United States of America, 108, 34653472 .

7. MacDonald D., Crabtree J. R., Wiesinger G., Dax T., Stamou N., Fleury P., et al. (2000) Agricultural abandonment in mountain areas of Europe: Environmental consequences and policy response. Journal of Environmental Management, 59, 47-69.

8. Moreira F., \& Russo, D. (2007) Modeling the impact of agricultural abandonment and wildfires on vertebrate diversity in Mediterranean Europe. Landscape Ecology, 22, 1461-1476.

9. Lietuvos Respublikos Žemès ūkio ministro įsakymas :Dèl žemės fondo apskaitos taisyklių patvirtinimo, 2002.(Order of the Minister of Agriculture of the Republic of Lithuania „On Approval of Land Fund accounting rules“). “, 2002, $7^{\text {th }}$ of August, No. 302, Vilnius. (in Lithuanian)

10. Lietuvos Respublikos Žemès Ūkio Ministro İsakymas „Dẻl Apleistų Žemès Ūkio Naudmenų Plotų Nustatymo Tvarkos Aprašo Patvirtinimo. 2013 (Order of the Minister of Agriculture of the Republic of Lithuania, 2013. On Approval of the Description of the Procedure for the Determination of Abandoned Farmland Land Areas"),., 21th of Marth, No. 3D-212, Vilnius. (in Lithuanian).

11. Prasad S., Thenkabail. (2016) Remotely Sensed data characterization, classification, and accuracies. Taylor @ Francis Group, LLC.

12. Prishchepov A. V., Radeloff V. C., Baumann M., Kuemmerle T., Müller D. (2012) Effects of institutional changes on land use: Agricultural land abandonment during the transition from state-command to marketdriven economies in post-Soviet Eastern Europe. Environmental Research Letters, 7, 024021 (13 pp.).

13. Ramankutty N., Gibbs H. K., Achard F., DeFries R. S., Foley J. A., \& Houghton R. A. (2007) Challenges to estimating carbon emissions from tropical deforestation. Global Change Biology, 13, 51-66.

14. Region Growing Algorithm. In the internet site: https://fromgistors.blogspot.com/p/usermanual.html?spref=scp

15. Richards J. A., Jia X. (2006) Remote Sensing Digital Image Analysis: An Introduction. Berlin, Germany: Springer.

16. Stoate C., Boatman N. D., Borralho R. J., Carvalho C. R., Snoo G. R. D., Eden P. (2001) Ecological impacts of arable intensification in Europe. Journal of Environmental Management, 63, 337-365.

17. Suziedelyte Visockiene J., Tumeliene E., Maliene V. (2019) Analysis and identification of abandoned agricultural land using remote sensing methodology. Land Use Policy, 82 (2019) 709-715.

\section{Information about authors:}

Eglè Tumelienè, PhD student at the Institute of Land Management and Geomatics, Vytautas Magnus University Agricultural Academy. Address: Universiteto str. 10, LT-53361 Akademija, Kauno r., Lithuania. Lecturer at Department of Geodesy and Cadastre, Vilnius Gediminas Technical University, Sauletekio av. 11, Vilnius, LT10223, Lithuania e-mail: egle.tumeliene@vgtu.lt

Jūratė Sužiedelytė Visockienė, prof. at Department of Geodesy and Cadastre, Vilnius Gediminas Technical University, Sauletekio av. 11, Vilnius, LT-10223, Lithuania, e-mail: jurate.visockiene@vgtu.lt 